\title{
Expanding the concept of Ba: managing enabling contexts in knowledge organizations
}

\section{Rivadávia Correa Drummond de Alvarenga Neto}

Chun Wei Choo

\author{
Fundação Dom Cabral (FDC), Brazil \\ Anima Educação, Brazil. KMRC - \\ University of Toronto, Canada
}

Faculty of Information Studies University of Toronto, Canada KMRC - University of Toronto, Canada

This paper investigates and analyses the concept of ba or enabling context - in the fields of information science, management/business and information systems literature in order to understand its conceptual evolution, discussions, applications and expansion since its introduction in 1998 by Nonaka et al. (Nonaka and Konno, 1998; Nonaka et al., 2000; Nonaka and Toyama, 2002; Nonaka et al., 2006). The qualitative methodology is bibliographic and comprises - among others - the methods of citation analysis and content analysis. A resulting selection of 135 papers, 4 dissertations/theses and 4 books constituted the research's final database. Data analysis consisted of three flows of activities: data reduction, data displays (conceptual maps) and conclusion drawing/verification. The results point out to the identification of four major groups of enabling conditions - social/behavioral, cognitive/epistemic, informational and business/managerial - which can be singly or freely combined into different knowledge processes - creation, sharing/transfer and use - occurring in different levels of interactions - individual, group, organizational, interorganizational. The conclusions suggest that the concept of ba and its underlying concepts are indeed sine qua non conditions for organizational knowledge creation and innovation processes, though ba is still both theoretically and empirically under-explored. Concerning the management of enabling contexts in knowledge organizations, the study revealed that the main arising challenges rely on the implementation and development of the issues comprised on the four groups of enabling conditions identified, most especially social/behavioral and business/managerial. 
Keywords: the concept of ba; ba; enabling context; enabling conditions; enabling knowledge creation; knowledge management; Nonaka.

Recebido em 16.06.2011 Aceito em 30.07.2011

\section{Introduction}

Knowledge creation is a fragile organizational process, particularly towards the nature of knowledge itself: fluid, dynamic, intangible, tacit and explicit, embodied in individual and groups, socially constructed, and constrained by individual and organizational barriers (von Krogh et al.1997,2000). In this paper, knowledge is approached through a constructionist perspective, as human cognition is not an act of representation and not just a machine for information processing and logical reasoning. In the constructionist perspective, cognition is an act of construction and creation (Maturana and Varela,1987), as well as knowledge is tacit, explicit and cultural $(C h o 0,1998)$. Knowledge resides in one's cognition as well as in between creative heads with synergetic purposes (Alvarenga Neto,2005, 2008).

Organizational knowledge creation is generally associated with Knowledge Management (KM), which is a controversial, complex and multifaceted subject. In spite of the fact that the term (KM) is not yet stable, there's been a growing interest worldwide within the past two decades - from academics to practitioners - in the management of organizational knowledge and its related topics, such as "organizational epistemology" (Tsoukas,2005), "knowledge creation processes" (Choo,1998), "knowledge-based theory of the firm" (Nonaka et al.,2006), "enabling context and conditions" (von Krogh et al., 2000)", "knowledge types" (Blackler, 1995), "knowledge assets" (Boisot, 1998) and "knowledge taxonomies" (Alavi and Leidner, 2001), among others.

In our studies within the last ten years, concerning the management of knowledge in world-class organizations, similar topics and approaches have been discussed, but above all, we've stressed out three main concerns: (i) a long standing misinterpretation that considers knowledge management and information management (IM) as synonyms. We shall call this "information reductionism", as the "map is not the territory" (Tsoukas, 2005). IM is just one of the components of KM, as KM also incorporates concerns as to the creation, sharing and enabling context/conditions for organizational knowledge creation; (ii) a long overlooked topic in the KM literature: KM implementation processes (Alvarenga Neto et al.,2009); and finally (iii) an empirically underexplored concept: "the concept of ba" or "enabling context", the ontological platform for knowledge creation.

As we have addressed these first two concerns in different publications within the past decade, we have decided to move on and thoroughly examine/discuss the concept of ba or the enabling context for 
organizational knowledge creation. To justify our decision, we argue that the literature concerning these specific topics is scarce, not publicized in mainstream business or information science journals - with a few exceptions - and not regarded as academically relevant through the use of bibliometric methods, such as citation analysis. There is also a knowingdoing gap concerning a process that is highly embedded and firm-specific:

"[...] Knowledge originates in ba, and therefore the concept of ba assumes a particular importance in organizational knowledge creation theory. While ba is theoretically relevant, it is also empirically under-explored." (Nonaka et al., 2006)

Of special relevance to this paper is a set of studies conducted by one of the authors - Alvarenga Neto $(2005,2008)$ and Alvarenga Neto et al. (2009) - as the concepts of ba, enabling context and enabling conditions turned out to be one of the main results of his studies. This author proposed a KM integrative conceptual mapping proposition as a result of his research of multiple case studies in world class organization within the past decade. These multiple case studies involved KM initiatives of 23 international firms, such as 3M, Dow Chemical, Xerox, PricewaterhouseCoopers, Siemens, CTC (Brazil's Sugarcane Technology Center), Ernst \& Young, British Telecom, Microsoft, Novartis and Chevron, among others. The main results suggested that (i) these organizations were not "managing knowledge", but rather managing the context and readiness where knowledge is socially constructed, produced and shared, and (ii) the main challenges facing organizations committed to $\mathrm{KM}$ have its focus on change management, cultural and behavioral issues and the creation of an enabling context that favors the creation, use and sharing of information and knowledge.Due to the fact the the concept of ba or the idea of an enabling context turned out to be one of the main (or the main) results, we argue for the need to proceed for further exploration of the concept of ba. Therefore, our main objective in this paper is to investigate and analyze the concept of ba - or enabling context - in the fields of information science, management/business and information systems literature in order to understand its conceptual evolution (if any), discussions, applications and expansion since its introduction in 1998 by Nonaka et al. (Nonaka and Konno, 1998; Nonaka et al., 2000; Nonaka and Toyama, 2002; Nonaka et al., 2006). This paper is structured in five major parts: (i) this introduction, (ii) the methodology (iii) the literature review, (iv) data analysis and (v) conclusions. The study and its results shall be presented in the lines below.

\section{Methodology}

The qualitative methodology is bibliographic in nature, comprising among others - bilbiometric methods of citation analysis and content analysis. To begin with, tools such as "citation report" and "cited reference search", among others, available at the ISI Web of Knowledge e-resource

Perspectivas em Ciência da Informação, v.16, n.3, p.2-25, jul./set. 2011 
were used. Part of the research's rationale involved searching the Web of Knowledge (ISI) having "ba" or the "concept of ba" as descriptors combined along with its mainstream author in the business and management field, Ikujiro Nonaka. The following results were found (FIGURES 1 and 2):

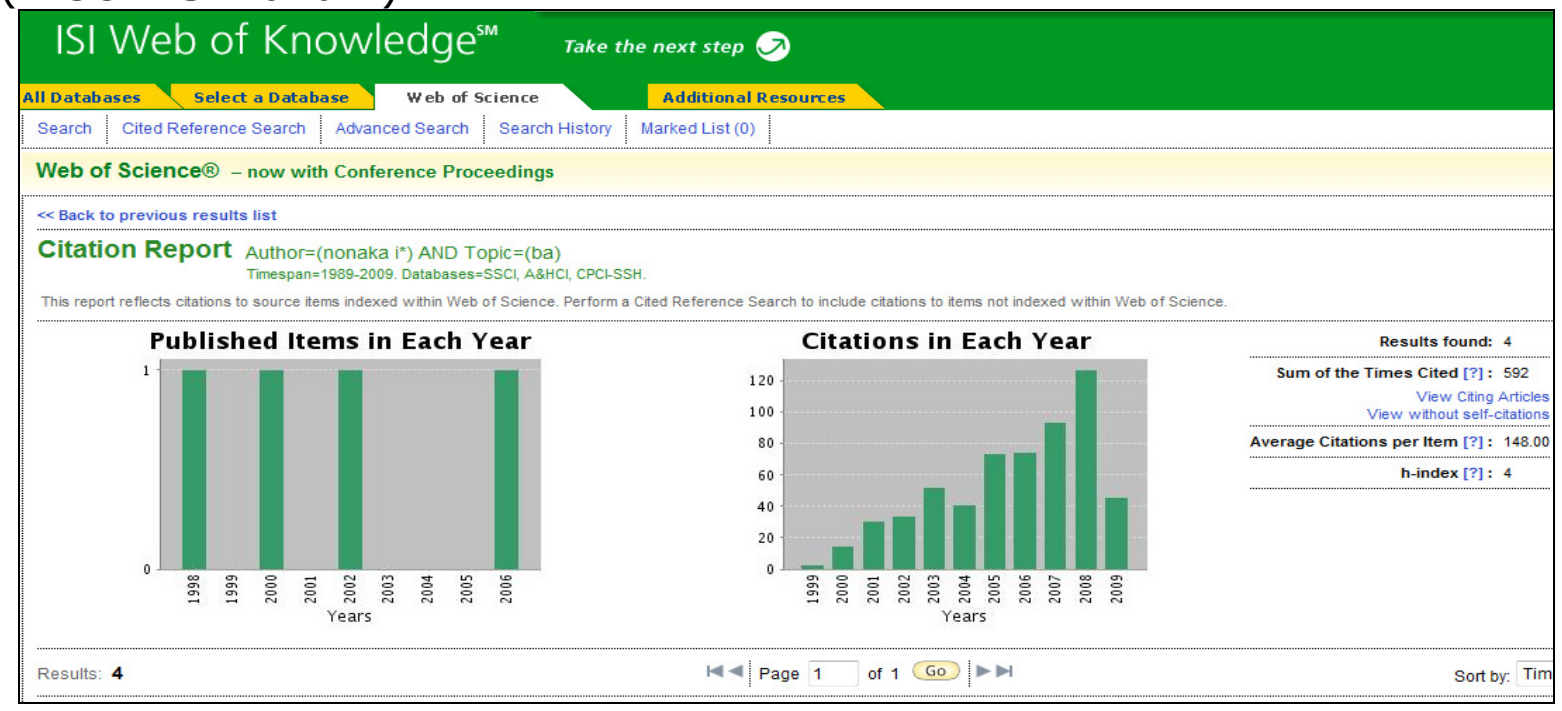

Figure 1: Citation report for "Nonaka" and "ba". Source: Web of Knowledge. Access in March, 2009.

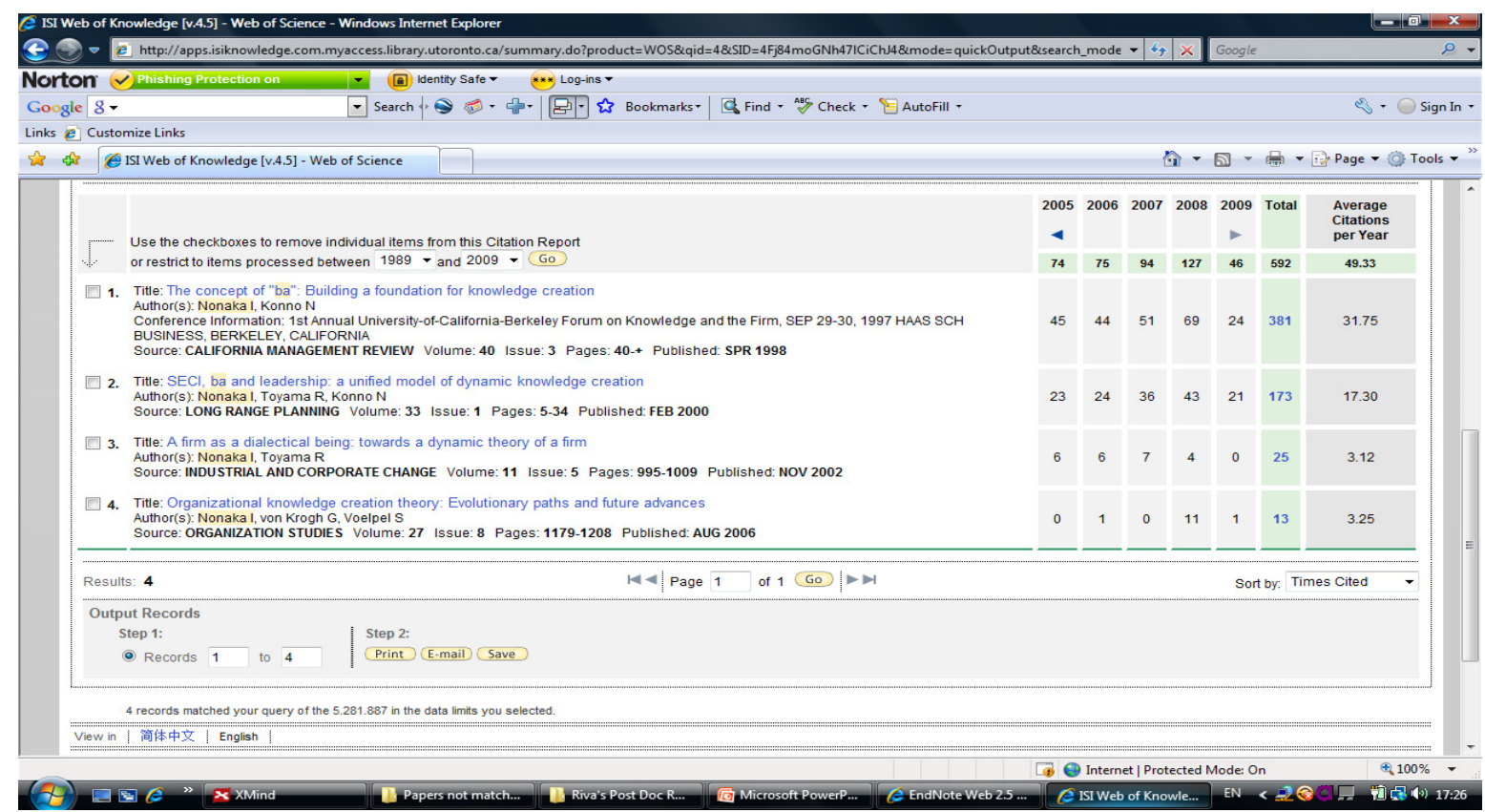

Figure 2: Citation report for "Nonaka" and "ba". Source: Web of Knowledge. Access in March, 2009.

The results demonstrate that with an $\mathrm{H}$-Index of 4 (which means that four papers have been cited more than four times, excluding selfcitations), four of Nonaka's papers (with the search criteria adopted above) have been cited 592 times since 1998 in papers all over the world, with an average of 49,33 citations per year. Therefore, to begin with, the research's database comprised a total of 598 papers, as we also chose to include two of Nonaka's papers about ba that were not contemplated by 
an $\mathrm{H}$-index of 4, but, after all, regarded as relevant in order to analyze the evolution of the author's ideas, concepts and applications through a chronological perspective. Hereafter, we'll refer to Nonaka's original papers about ba as "the first generation papers" and all of the other citing papers of Nonaka's ba or enabling context concepts as "the second generation papers". These 592 papers (H-Index 4) were grouped by the number of times these second generation papers were cited by others: more or less than 20 citations. The number 20 was intentionally chosen, as to have a minor group of second generation papers (32 papers) that were highly cited by others, and a major group of papers that haven't had the same repercussion. This criterion was helpful in order to reinforce our initial presumption of empirical under-exploration of ba. Consequently, we also decided to examine the citation report of Nonaka's two papers not contemplated with an $\mathrm{H}$-index of 4 and all of the papers that cited those two.

These "second generation papers" were examined by searching within each document for the descriptors mentioned above with the aid of "EndNoteWeb" and "EndNote" softwares, besides the search tools available in "Adobe Acrobat" and "Microsoft Office". Duplicates were eliminated and a few papers were not available. At this point, it's important to mention that even Shimizu's(1995) paper - uncountably cited and regarded by the first generation papers as the cornerstone of the baprinciple in Nonaka's work (along with Nishida's, 1990) - was not available, even in e-resources such as Factiva, Business Abstracts and Proquest, among others. An extra-search effort in different interconnected libraries and e-resources was also conducted showing no results. After this criterion - a data reduction process in data analysis - the number of second generation papers selected so far for manual analysis went from $593^{i}$ to 50 papers, which added to the 4 "first generation papers" comprised a total of 54 papers to begin with.

After these first search criteria partial results, it was our decision to go beyond bibliometrics and expand our research database in order to look for more papers discussing the concept of ba and its underlying concepts. For this purpose, we also decided to include descriptors such as "enabling context", "enabling conditions" and "enabling knowledge creation" to the existing descriptors ("ba", "concept of ba" and "Nonaka"), as these descriptors were highly cited in the references of the "first generation papers". Consequently, based on the same criteria described above, the search was expanded to the following (FIGURE 3): (i) eresources; (ii) e-journals containing "Knowledge Management" in their titles. Search criteria involved the use of descriptors' search within title, abstract and keywords; (iii) Google Scholar (page rank/relevance availability of paper online considered, elimination of duplicates) and Google Book Search (searching for material not previously published in the form of papers in journals) - extra search criteria using authors' names from the "first generation papers" or authors cited by the "first generation papers"; (iv) papers cited in the references of the "first generation papers", papers sent to us by peers or simply "serendipity".

Perspectivas em Ciência da Informação, v.16, n.3, p.2-25, jul./set. 2011 


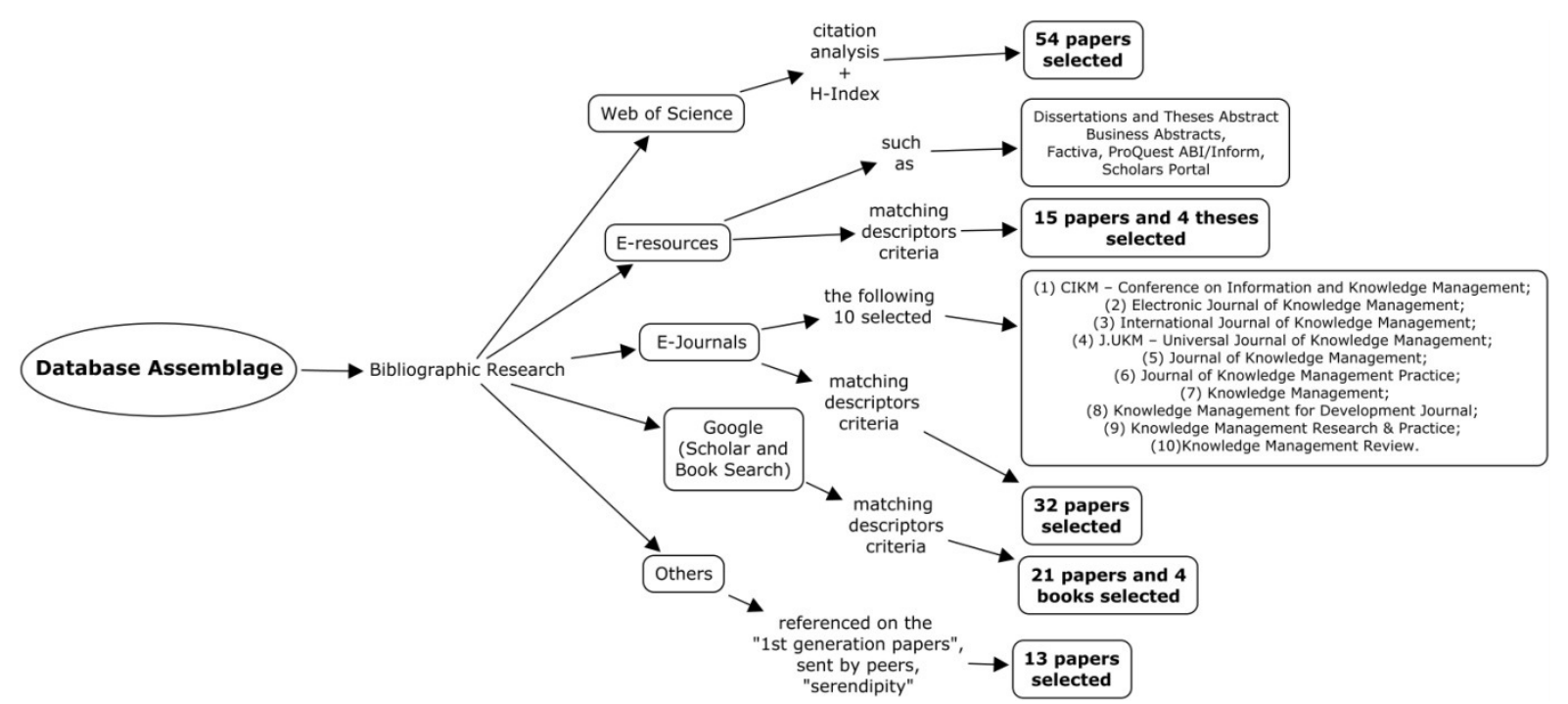

Figure 3: Research's database assemblage. Source: developed by the authors.

A resulting selection of 135 papers, 4 dissertations/theses and 4 books constituted the research's database, which were all selected for manual analysis. It's important to heed attention to the fact that the bibliographic research proposed here intends to be comprehensive, but never exhaustive. The time-span comprehends papers published from 1991 to 2009 and the authors were academics and practitioners from many different counties such as Japan, Finland, Portugal, Brazil, Canada, the Netherlands, Spain, France, Greece, Great Britain, South Korea, USA, Australia, China, Italy, Israel, Germany and South Africa among others.

As for data analysis of the research's database, it consisted of three flows of activities: data reduction, data displays (conceptual maps) and conclusion drawing/verification (Miles and Huberman,1984).Displays in the form of conceptual and mind maps were built and proved useful for all of the three flows of activities, constituting analytical categories. Seven data reduction cycles were necessary in order to make the research data feasible to incorporation in this paper. In the following section, the literature review will be presented, followed by a discussion of data analysis.

\section{Literature Review}

Following the methodological choices stated above, the literature review presented hereafter is based on the "first generation papers" written by Nonaka and colleagues (Nonaka and Konno, 1998; Nonaka et al., 2000; Nonaka and Toyama, 2002; Nonaka et al., 2006) about the concept of ba. Their propositions for a dynamic organizational knowledge creation theory are synthesized in FIGURE 4, where ba is one of the components: 


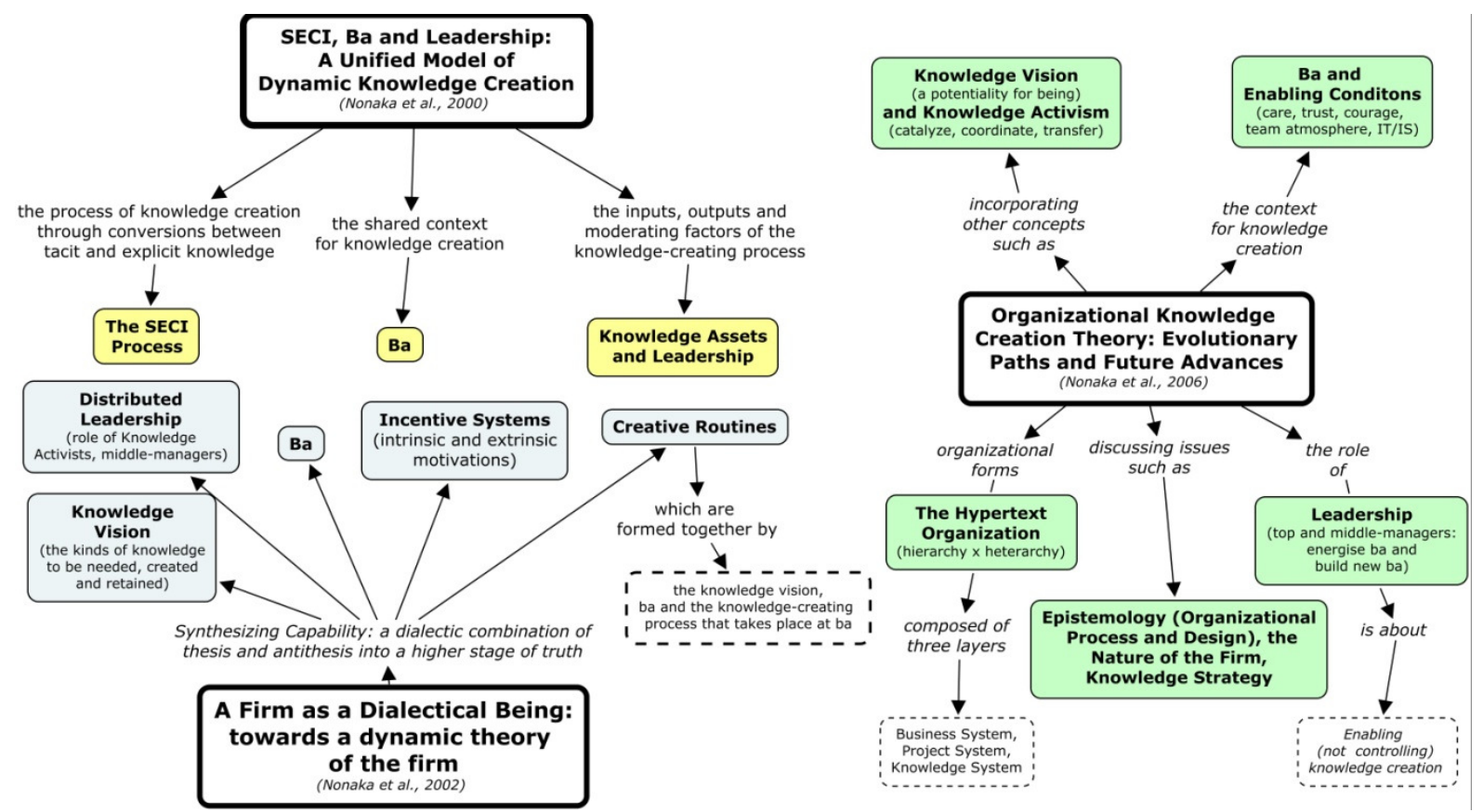

Figure 4: Synthesis of Nonaka's et al. (2000, 2002, 2006) propositions towards a knowledge-based theory of the firm having ba as one of the components. Source: adapted by the authors.

According to Nonaka et al. (2006), the context for knowledge creation is ba and a central purpose of organizational knowledge creating theory is to identify conditions enabling knowledge creation in order to improve innovation and learning. As stated earlier, Nonaka et al. (2006) attest the uppermost relevance of ba and the fact that it is empirically under-explored. This not only quite justify our efforts in this research, but also opens up for the exploration of further contributions about ba, enabling context and enabling conditions as well as the exploration of ba outwards the SECI Process.

Nonaka and Konno (1998) started the discussion about the concept of ba by presenting a seminal question: "Is it possible to actually manage knowledge like other resources?" In order to address this question, they introduced the concept of "ba", roughly translated into the English word "space". They state that the concept of "ba" was proposed by Japanese philosopher Kitaro Nishida (1990) and further developed by Shimizu (1995). This "space for emerging relationships" can be physical (e.g., office, dispersed business space), virtual (e.g., e-mail, teleconference), mental (e.g., shared experience, ideas, ideals), or any combination of them. It is stressed that the difference between "ba" and ordinary human interaction is the concept of knowledge creation: "we consider 'ba' to be a shared space that serves as a foundation for knowledge creation" (Nonaka \& Konno, 1998).

From such perspective, knowledge exists and resides in "ba", or, put in the authors' words, "knowledge is embedded in "ba" or the shared spaces". From their epistemological perspective, Nonaka and Konno (1998) outline the fact that knowledge cannot be separated from "ba", or otherwise it will become information. Information resides in media and 
it's tangible and, in its turn, knowledge resides in "ba" and it is intangible. They emphasize the idea, drawn from an existentialist framework, that the key platform of knowledge creation is this "phenomenal" place of knowledge that can emerge in individuals, working groups, project teams, informal circles, e-mail groups or front-line contact with customers, among others. Therefore, it exists at many levels and these levels may connect to form a "greater ba", known as "basho". They also suggest that the use of knowledge requires the concentration of knowledge assets at a certain time and space and they name this concept as "organic concentration"

In Nonaka \& Konno's (1998) view, 'Ba' offers an integrating conceptual metaphor for Nonaka's (1991) SECI model of dynamic knowledge conversions and it is discussed from this perspective - that organizational knowledge creation is a dynamic and continuous interaction between tacit and explicit knowledge. Four types of "ba" correspond to the four stages of the SECI Model (FIGURE 5):

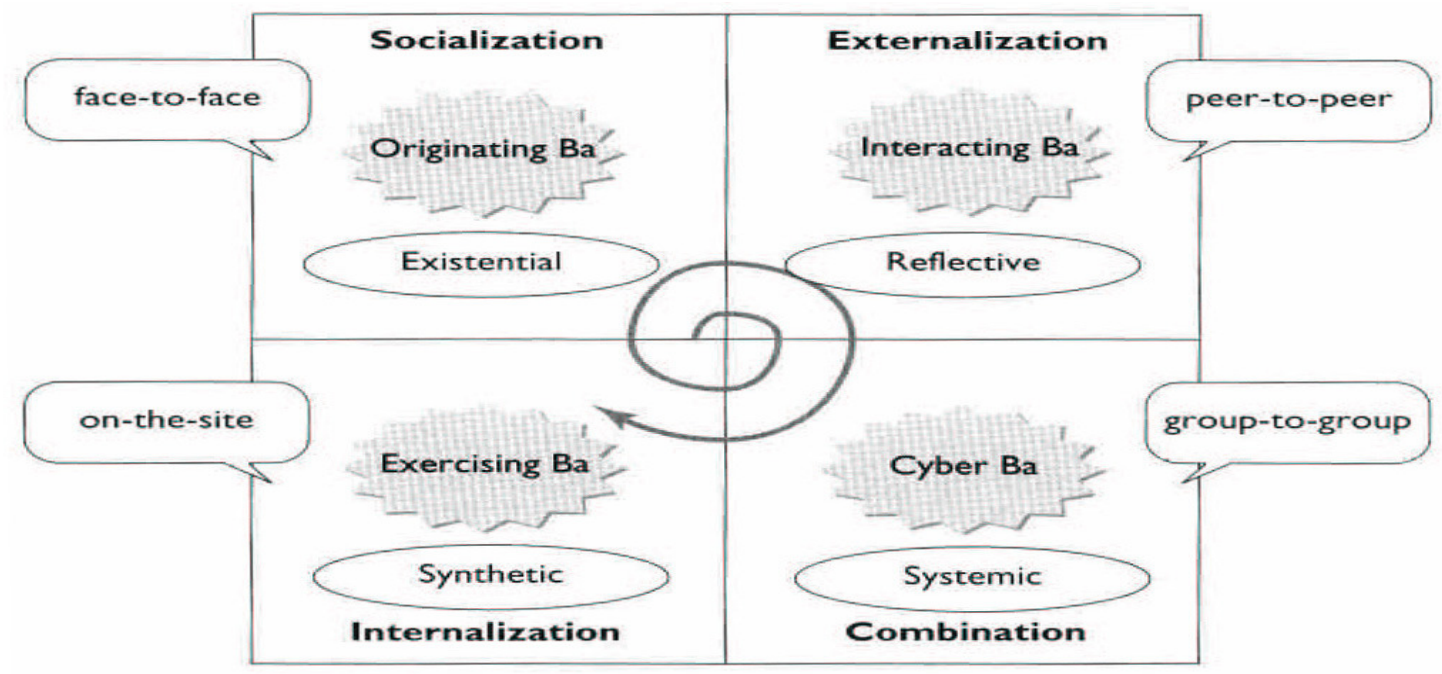

Figure 5 - The Fours Characteristics of Ba . Source: Nonaka and Konno, 1998.

Nonaka et al.(2000) enhanced the idea of ba proposed by Nonaka \& Konno (1998) in order to understand the dynamic process in which an organization creates, maintains and exploits knowledge. For this, they proposed a model of knowledge creation (FIGURE 4) where ba is one of the components. This model consists of three elements (i) the SECI Process, (ii) 'ba'- the shared context in motion for knowledge creation and (iii) knowledge assets. To certain extent, Nonaka et al. (2000) shed more light on the concept of ba by suggesting that the four types of ba are defined by two dimensions of interactions: (i) the type of interaction (individually or collective) and (ii) the media used in such interactions, whether face-to-face contact or virtual media such as books and e-mails. The authors retake Nonaka and Konno's (1998) original assumption to affirm that ba exists at many ontological levels and these levels may be 
connected to form a greater ba or "basho": individuals form the ba of teams, which in turn form the ba of the organization and so on.

Nonaka and Toyama's (2002) goal is the proposition of a dynamic theory of the firm (or a knowledge-based view of the firm) where ba is quintessential (FIGURE 4). They argue that a firm can create new knowledge and capability that go beyond the balancing point in the existing frontier with its synthesizing capability, which is embedded in its knowledge vision, its ba, its creative routines, its incentive systems and its distributed leadership. Finally, Nonaka et al. (2006) discuss ba and enabling conditions such as care, trust, courage, teams atmosphere and information technology, among others, as well as other issues such as the concepts of "knowledge vision", "knowledge activist" and the "hypertext organization".

At this point of our literature review, it is already possible to establish links between an eastern/Japanese concept of ba and its similar western approach - mainly represented in the works of von Krogh (1998) and von Krogh et al. (1997, 2000) - involving concepts and ideas such as "enabling context", "enabling conditions", "knowledge activists" and "care in knowledge creation". These discussions and the analysis of the "second generation papers" will be our goal in the next section, as we'll try to understand the concept of ba's discussion, development, applications and expansion since its introduction by Nonaka et al. (1995, 1998, 2000, 2002, 2006).

\section{Data analysis}

In this section, we'll briefly analyse "the second generation papers" comprised in our research's database. Through our data analysis processes, particularly in the phases of data reduction, five major categories emerged as ways of grouping our research findings, namely (FIGURE 6): (i) conceptual/theoretical: where the concept of ba was used for - or as a basis of/part of - new conceptual or theoretical propositions/ discussions; or papers where further theoretical and empirical support was proposed to the concept of ba by Nonaka and colleagues; (ii) social/behavioral: related to norms and values that guides interactions and relationships, such as trust, care, empathy, attentive enquiry and "tolerance to "honest mistakes", among others; (iii) cognitive/epistemic: related to common knowledge or shared epistemic values and commitments; (iv) informational: regarding IM (information management), IT (information technology) and IS (information systems), as well as information/communication processes, and (iv) business/managerial: related to general organizational issues, such as strategy, processes, structure, support, resources and organizational culture, among others.

With the exception of the first major category (conceptual/theoretical), the remaining four - henceforth called "the four groups of enabling conditions" - were observed in different knowledge processes - creation, sharing/transfer, use - and in different levels of 
interaction - individual, group, organizational, inter-organizational (FIGURE 7). They were also not solely use in the context of the SECI process (e.g. Jyrama and Ayvari, 2006; Miles et al., 2000), as advocated by Nonaka and colleagues (1998, 2000, 2002, 2006). This might be seen as an evolution in terms of application of ba.

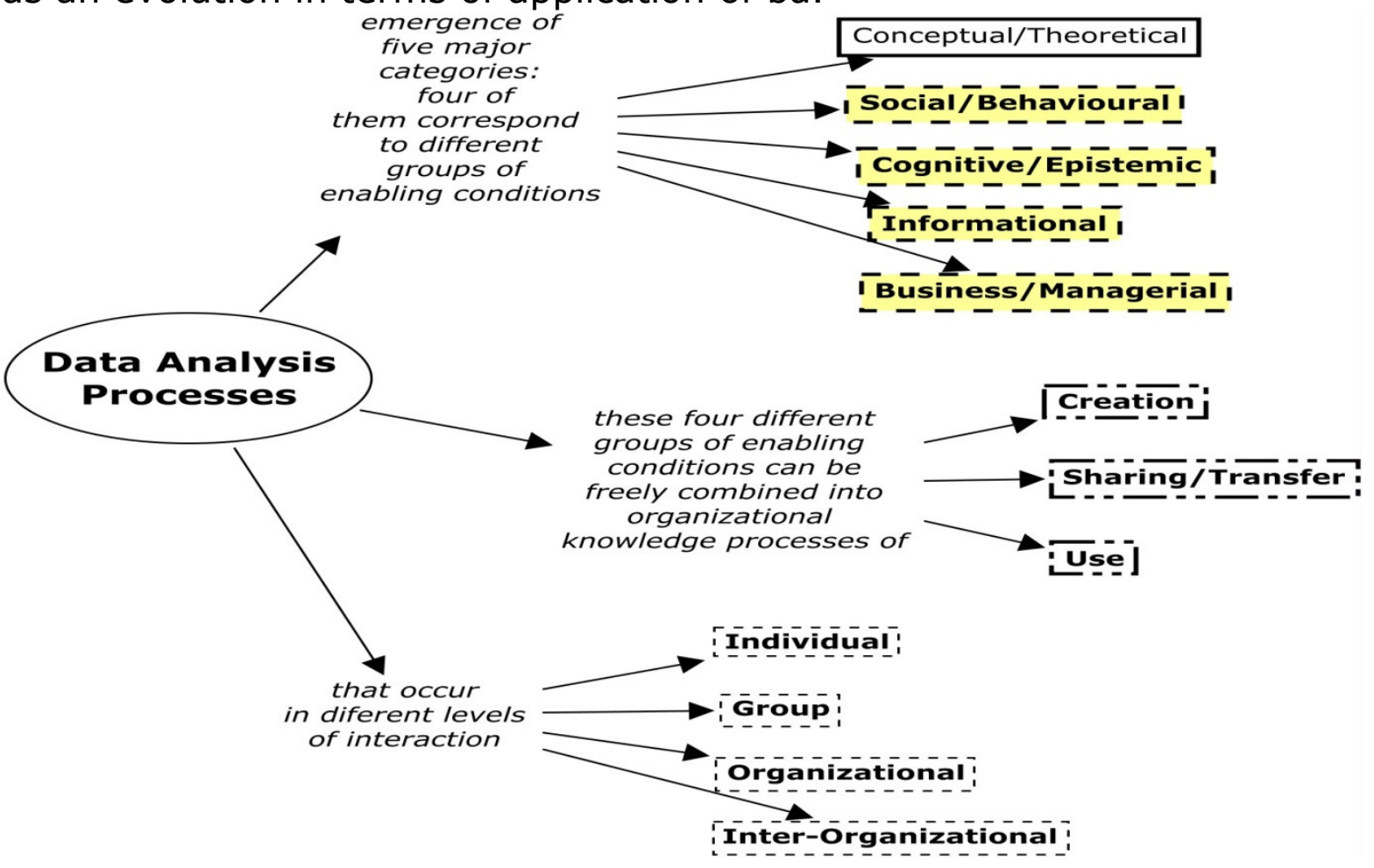

Figure 6: "Four Major Groups of Enabling Conditions" as a result of data analysis processes. Source: developed by the authors

Concerning the first major category - conceptual/theoretical (FIGURE 8), our analysis demonstrates that the concept of ba is still theoretically under explored, although its discussion has somehow been expanded to different contexts or as a component of other theoretical propositions. Most of what has been added to the theoretical development of the concept of ba is credited to Nonaka and colleagues, through the means of concepts, discussions and case studies. At this point of our analysis, it's important to bear in mind that different groups of enabling conditions support different ba in different ways, as well as the fact that ba and enabling context are used as synonyms. These theoretical/conceptual findings are synthesized in FIGURE 7: 


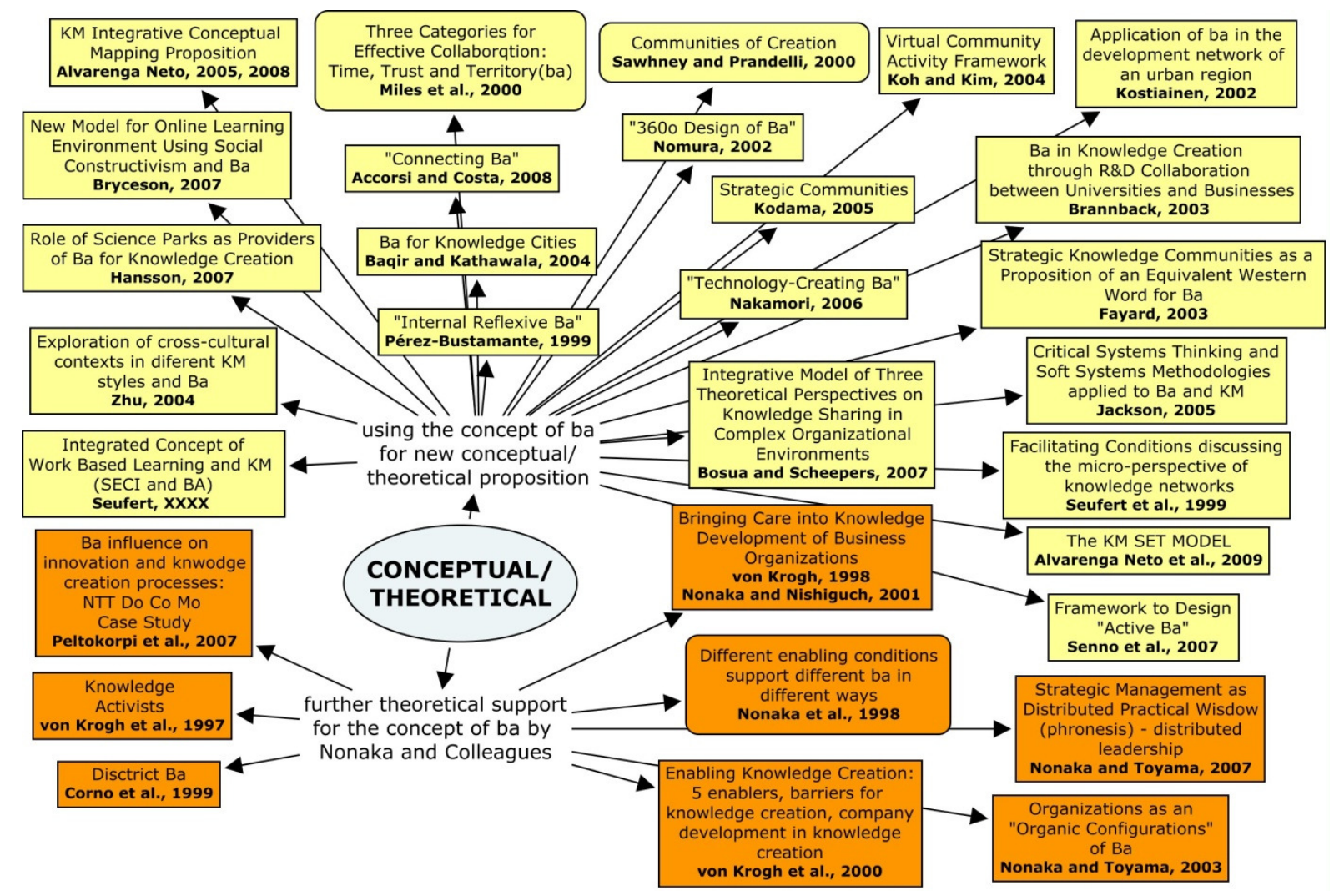

Figure 7: Theoretical/Conceptual analysis - Source: developed by the authors.

exposure As mentioned above, the four remaining major categories constitute four different groups of enabling conditions. These groups of enabling conditions can be used singly or in any combination with the purpose of creating or enhancing an organization's enabling context or ba.

The first group of enabling conditions is social/behavioral and involves norms and values that guide relationships and interactions in order to create a fertile ground for knowledge creation, sharing and use, as well as for facilitating innovative thinking. Our main findings suggest that the following issues should be taken into account, as they give rise to particular behaviors that should be communicated to and pursued by personnel and managers, as well as serve as guidelines for HRM assessments, such as hiring, training, utilizing, maintaining and compensating:

care, mutual trust, lenience in judgment, active empathy, courage and access to help (Inkpen, 1996; von Krogh, 1998; Burton, 2002; Lee and Choi, 2003; von Krogh et al., 2008);

2005);

tolerance to "honest" mistakes and mutual respect (Alvarenga Neto,

actively encouragement of participation, nurture of innovating language while avoiding hypercorrection (von Krogh et al., 2000);

accessibility of individuals and attentive inquiry (Nonaka and Nishiguch, 2001);

interaction and open dialogue (Gold et al., 2001; Sabherwal and Becerra-Fernandes, 2003), collaboration (Lee and Choi, 2003); 
autonomy of freedom (Ford and Angermeir, 2005);

contextual social interactions and evolving relationships (Peltokorpi et al., 2007).

Our second group of enabling conditions - cognitive/epistemic, is related to common knowledge or shared epistemic values and commitments. It's a sine qua non condition the existence of shared beliefs and ideas, as well as people with different backgrounds and mental models, enabling a context where contradictions and diverging ideas are seen as positive issues, not as obstacles for knowledge creation and innovation. Our findings are structured around the following issues that might constitute guidelines, especially into addressing complex problems and the need for developing an organization's accelerated solutions environment:

to a great variety of data, insights, questions, ideas and problems (von Krogh et al., 1997);

application of creative techniques for metaphors, analogies and insights (von Krogh et al., 1997; Burton, 2002)

existence of a sound mix of people from various cultural backgrounds and functional areas (von Krogh et al., 1997), existence of diverse perspectives and backgrounds (Gold, et al., 2001; Peltokorpi et al., 2007) and existence of interorganizational communities formed by people with different mind-sets and mental models (von Krogh et al., 2008);

existence of formal and informal groups or communities (e.g., microcommunities of knowledge) with their own rituals, languages, norms and values (von Krogh et al., 1997); creation of shared spaces and shared goals (Lechner and Dowling, 2003; von Krogh et al., 2008; Balestrin et al., 2008; Brannback et al., 2008), and the sharing of mental models (Burton, 2002);

development of dialectical thinking (Nonaka and Toyama, 2002) and a legitimate language (von Krogh et al., 2000), as well of awareness of a company paradigms, in terms of values, strategic intention and mission (von Krogh et al., 2000);

provision of enabling conditions such as creative chaos (Inkpen, 1996), intention and requisite variety (Johnson, 2000);

production and sharing of practical knowledge, meeting in different constellations and creation of common knowledge (Alavi and Leidner, 2001; Roth, 2003).

The third group of enabling conditions is informational, regarding IT (information technology), IS (information systems) and IM (information management), as well as information/communication processes. Our findings are suggestive that a combination of multiple IT/IS tools, systems 
and applications - guided by IM processes design based on a company's strategic issues, knowledge vision and communication strategy - are powerful enabling conditions, especially in the knowledge processes of sharing/transferring and use, within the interactional levels of groups and organizations. It's important to bear in mind that IT is only an enabler and not an end in itself. Here's a summary of tools, systems and applications cited in our analysis along with a few suggestions on the way they can be effectively applied:

internet, intranet, yellow pages, business information systems, groupware, databases, datawarehousing, datamining, document repositories, software agents, repositories of information, best practices and lessons learned (von Krogh et al., 1997,2000; Nonaka et al., 1998; Alavi and Leidner, 2001; Sabherwal and Becerra-Fernandez 2003; Chou and Wang, 2003; Lee and Choi, 2003);

information systems designed to support collaboration, coordination and communication processes as a mean to facilitate teamwork and increase an individual's contacts with other individuals (Alavi and Leidner, 2001);

e-mails and group support system in order to to increase the number of weak ties in organizations (Alavi and Leidner, 2001; Chou and Wang, 2003);

computer simulation and smart software tutors to support individual learning in intranet environments (Alavi and Leidner, 2001; Tee, 2005);

computer-mediated communication as a way to increase the quality of knowledge creation by enabling a forum for constructing and sharing beliefs, for confirming consensual information and for allowing expressing of new ideas (Alavi and Leidner, 2001);

problem-solving systems based on a technology like casebased reasoning (Sabherwal and Becerra-Fernandez, 2003);

virtual communities of practice (Pam and Leidner, 2003; Alvarenga Neto, 2005).

At last, the fourth major group of enabling conditions is business/managerial and the issues considered are ways that managers can, in fact, directly construct, influence, interfere and manage an organization's effective ba or enabling context by commitment and action. This group of enabling condition also considered businesses processes where the concept of ba was actually applied in different researches. Here is a summary of our findings that can be useful guidelines for the management of enabling contexts in knowledge organizations:

organizational culture: a critical issue to facilitate knowledge creation, a central issue to be shaped in a firm's ability to 
manage its knowledge more effectively and the most prominent enabler (Inkpen, 1996; Perez Bustamante, 1999; Gold et al., 2001; Lee and Choi, 2002; Roth, 2003; Alvarenga Neto, 2005; Adenfelt and Lagerstrom, 2006 von Krogh et al., 2008;);

organizational structure: involves organizational structure that foster solid relationships and effective collaboration, such as project teams, cross-divisional units and empowered divisions, among others (von Krogh et al., 2000; Lee and Choi, 2003); systems-based approach, hypertext organization (Gold et al., 2001, Nonaka et al., 2006); autonomous and self-organizing teams (Peltokorpi et al., 2007);

organizational and inter-organizational processes: involves the application or studies/research of the concept of ba into business processes such as the management of salesforces (Bennet, 2001), ex ante project risk (Cuellar and Gallivan, 2005), supply-chain (Wu, 2008), inter-organizational healthcare communities (von Krogh et al., 2008), firms in networks (Lechner and Dowling, 2003), transnational projects (Adenfelt and Lagerstrom, 2006), family business context (Brannback,et al., 2008), industrial districts (Corno et al., 1999) and collaborative inter-organizational R\&D projects (Johnson, 2000);

Human Resources Management and organizational learning initiatives/projects: regards reward systems linked to knowledge-sharing (von Krogh et al., 2008) and the existence of flexible learning objectives (Inkpen, 1996); the cultivation of care through incentive systems, mentoring and training programs in care based behavior, project debriefing and other forms of learning-oriented conversations (von Krogh, 1998); use of apprentice and mentors to transfer knowledge, brainstorming retreats or camps, employee rotation areas, OJT, learning-by-doing and learning by observation (Sabherwal and Becerra-Fernandez, 2003); development of adequate team-atmosphere (Zárraga and Bonache, 2005);

architectural innovations: creation of meeting and sharing organizational spaces/points (Balestri et al., 2003; Lechner and Dowling, 2003; Alvarenga Neto, 2008); design of virtual and physical layout and workplaces environments (von Krogh et al.,1997; Alvarenga Neto, 2005); promotion of regular knowledge conferences and supporting of microcommunities of knowledge (von Krogh et al., 2000); stimulus to social and informal gatherings (Bennet, 2001);

emergence of Knowledge Facilitators and Knowledge Activists: such as epistemologists, care specialists, knowledge 
managers, information analysts, CEO, CKO, project managers and middle managers, among others (von Krogh et al., 1997, 2000; Roth, 2003; Alvarenga Neto, 2005, Nonaka et al., 2006); a company as a knowledge activist (von Krogh et al., 2008); role of mediators as enablers in knowledge creation (Jyrama and Ayvaari, 2007);

leadership: concerns leadership styles and roles of leadership (von Krogh et al., 2008; Ford and Angermeier, 2004); leadership commitment (Inkpen, 1996); "selling of foresight" by providing overall direction and the knowledge vision of a firm (von Krogh et al., 1997,2000); leadership's tasks in constructing ba, creating enabling conditions and setting the pace for knowledge dynamism (Nonaka et al., 1998); phronesis (intellectual virtue) and flexible and distributed leadership (Nonaka and Toyama, 2007); role of topmanagement directing the knowledge-creation processes by creating visions and the role of middle-managers bridging topmanagement visions with the chaotic reality at front line, also managing and interlinking ba (Peltokorpi, et al., 2007);

strategy and knowledge Vision: communication of the company's strategy and knowledge visions (Alvarenga Neto, 2005); instill a knowledge vision (von Krogh et al., 2000; Peltokorpi et al., 2007).

Figure 8 illustrates the four different groups of enabling conditions: 


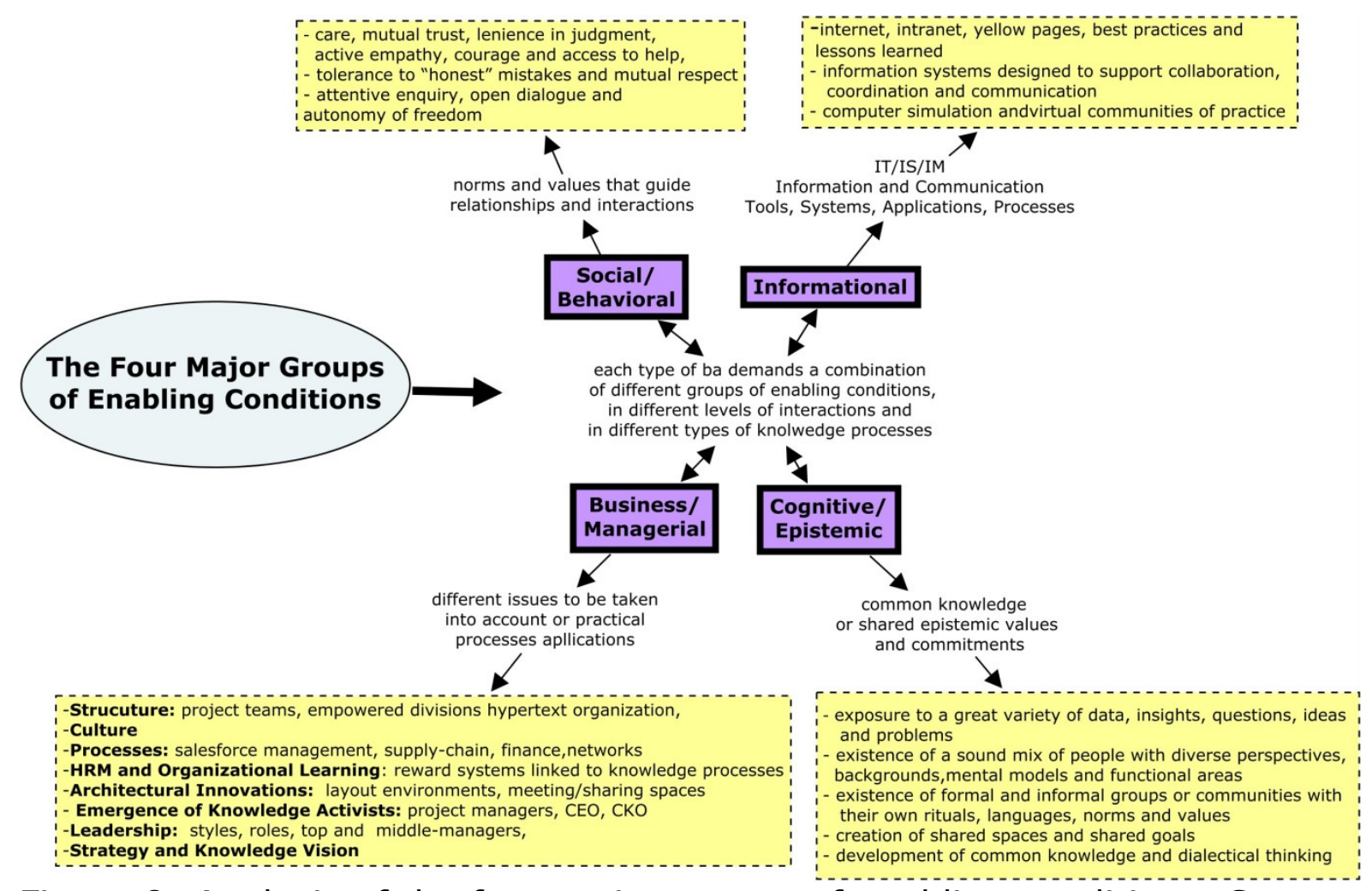

Figure 8: Analysis of the four major groups of enabling conditions. Source: developed by the authors.

\section{Conclusions}

This paper's main goal was to investigate and analyze the concept of ba - or enabling context - in the fields of information science, management/business and information systems literature in order to understand its conceptual evolution, discussions, applications and expansion since its introduction in 1998 by Nonaka et al. (Nonaka and Konno, 1998; Nonaka et al., 2000; Nonaka and Toyama, 2002; Nonaka et al., 2006). FIGURE 9 synthesizes the overall study and the expansion of the concept of ba, bringing light to its unique features such as concepts, forms, emergence, types, case studies, multiple discussions and applications, as well as suggestions for future research: 




Figure 9: Expanding the Concept of ba - Source: developed by the authors.

The results pointed out to the identification of four major groups of enabling conditions - social/behavioral, cognitive/epistemic, informational and business/managerial - which can be singly or freely combined into different knowledge processes - creation, sharing/transfer, use - that occur in different levels of interactions - individual, group, organizational, inter-organizational. (FIGURE 10): 


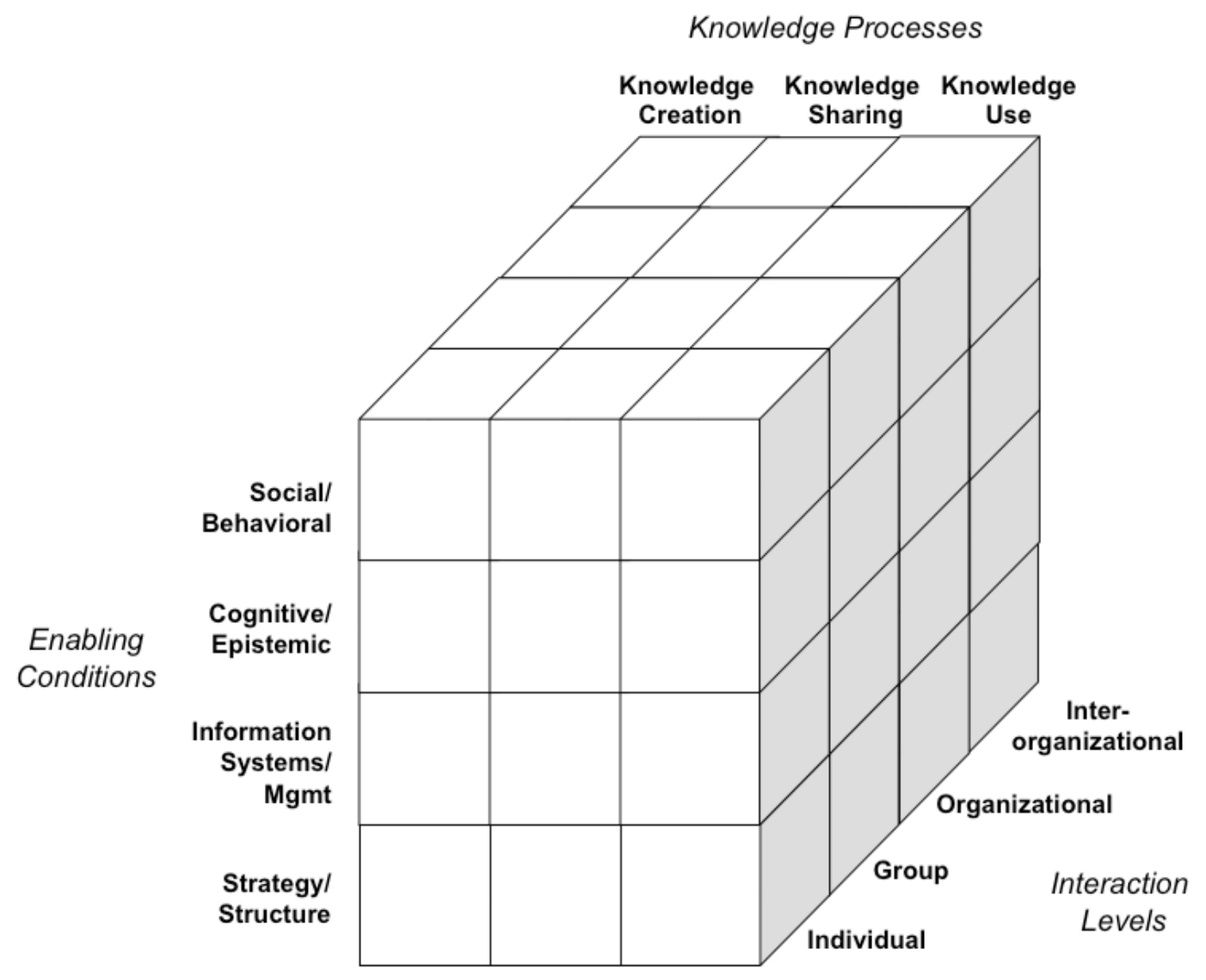

Figure 10. Framework for designing an Enabling Context in KM

These findings can be insightful for managers interested in creating and/or developing effective ba or enabling contexts to foster knowledge creation and innovation in their organizations, as they can utilize these frameworks to analyze, discuss, apply, manage and commit to specific combinations of enabling conditions based on their awareness of knowledge processes and levels of interaction.

The conclusions suggest that the concept of ba and its underlying concepts are indeed sine qua non conditions for organizational knowledge creation and innovation processes, though ba is still both theoretically and empirically under-explored. Nevertheeless, we have found that the concept has somehow been expanded as part of other theoretical discussions and/or in different contexts, but still demands further exploration and development. Concerning the management of enabling contexts in knowledge organizations, the study revealed that the main arising challenges rely on all of the issues comprised on the four groups of enabling conditions identified, most especially social/behavioral - norms and values that guide social contextual interactions, thus providing a fertile ground for knowledge creation and innovation - and business/managerial - concerning organizational culture and structure, change management, leadership and the development of new HRM systems for connecting knowledge assets and performance, thus achieving the necessary speed to agile, flexible and innovative in the $21^{\text {st }}$ century's knowledge society. A research agenda for ba is suggested in the 
fields of open innovation, social networks - such as wikis, blogs, social tagging, among others - and epistemic communities. As we speak, a research project is being conducted at Embrapa The Brazilian Agricultural Research Corporation - by one of the authors of this paper. The four groups of enabling conditions were identified at Embrapa, though we couldn't yet measure the importance of each and the overall results. Embrapa's just finished it's KM Model and building and energizing ba is where all the energy is being focused at (FIGURE 11). The results of the research at Brazil's Embrapa and its relations with the concept of ba will be published soon.

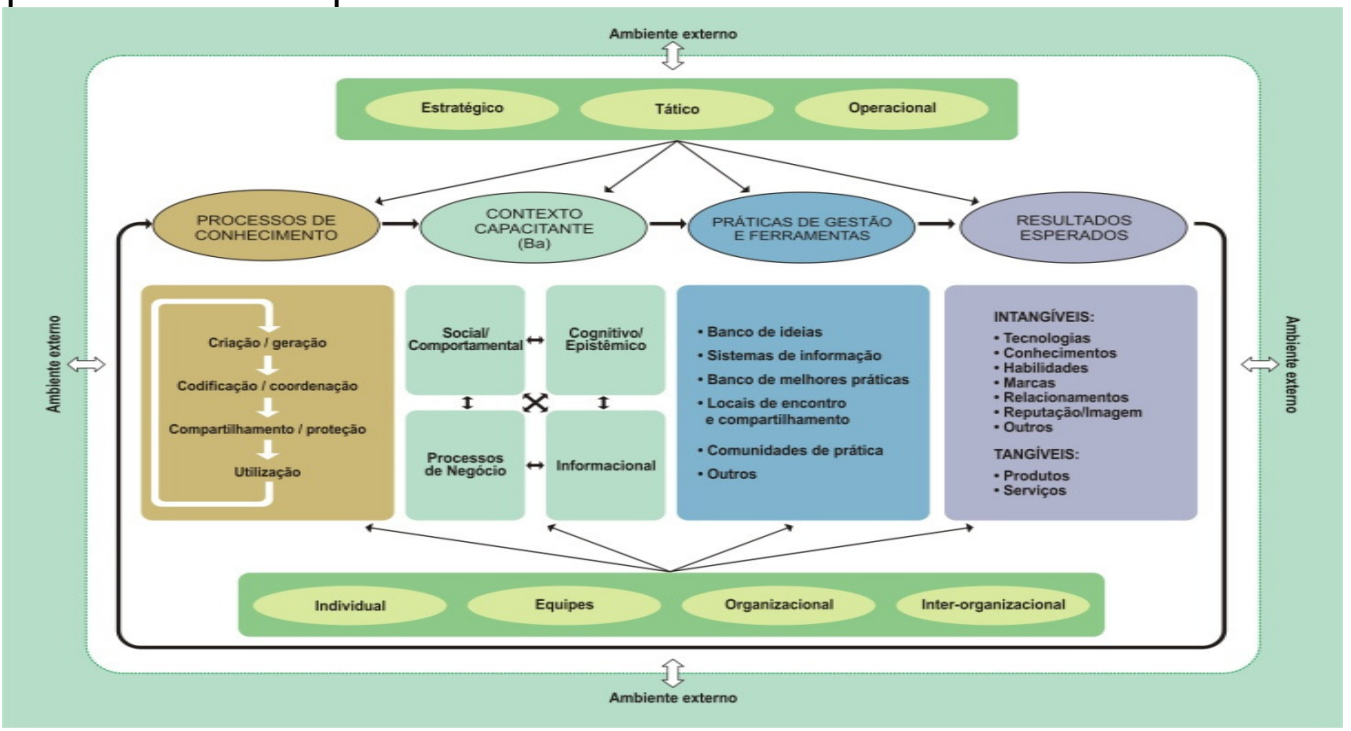

Figure 11. Brazil's Embrapa KM Model and ba. Source: developed by the authors.

\section{References}

ACCORSI, F. L. \& COSTA, J. P. (2007) Peer-to-peer systems consubstantiate the Ba concept. IN REMENYI, D. (Ed.) 8th European Conference on Knowledge Management. Barcelona, SPAIN, Academic Conferences Ltd.

ADENFELT, M. \& LAGERSTROM, K. (2006) Enabling knowledge creation and sharing in transnational projects. International Journal of Project Management, 24, 191-198.

ALAVI, M. \& LEIDNER, D. E. (2001) Review: Knowledge management and knowledge management systems: Conceptual foundations and research issues. Mis Quarterly, 25, 107-136.

ALVARENGA NETO, R. C. D. (2005).Gestão do conhecimento em organizações: proposta de mapeamento conceitual integrativo [Knowledge management in oganizations: an integrative conceptual mapping proposition] Tese [Doctoral thesis]. Ph.D. Escola de Ciência da Informação: UFMG, BRAZIL. 
ALVARENGA NETO, R. C. D. (2007) Knowledge management practices in Brazilian organizations - A conceptual shift towards "Ba". IN REMENYI, D. (Ed.). Stellenbosch, SOUTH AFRICA, Academic Conferences Ltd.

ALVARENGA NETO, R. C. D. (2008) Gestão do conhecimento em organizações: proposta de mapeamento conceitual integrativo [Knowledge management in oganizations: an integrative conceptual mapping proposition]. São Paulo: Editora Saraiva (Saraiva Publishers)

ALVARENGA NETO, R. C.D. \& LOUREIRO, R. S. (2008) Knowledge Management in the brazilian Agribusiness Industry: A Case Study at CTC Centro de Tecnologia Canavieira (Sugarcane Technology Center). IN OSULLIVAN, K. (Ed.). New York, NY, Academic Conferences Ltd.

ALVARENGA NETO, R.C.D., SOUZA, R.R., QUEIROZ, J.G. \& CHIPP, H. (2009) Implementation of a Knowledge Management Process within the Brazilian Organizational Context: the ONS (National Operator of the Interconnected Power System) Experience. $6^{\text {th }}$ International Conference on Intellectual Capital, Knowledge Management \& Organisational Learning. School of Information Studies, McGill University, Montreal, Canada. 1-2 Out 2009. Academic Conferences International: London.

BALESTRIN, A., VARGAS, L.M. \& FAYARD, P. (2008) Knowledge creation in small-firm network. Journal of Knowledge Management, 12, 94-106.

BAQIR, M.N. \& KATHAWALA, Y. (2004) Ba for knowledge cities: a futuristic technology model. Journal of Knowledge Management, 8, 83-95.

BENNETT, R. (2001) "Ba"as a determinant of salesforce effectiveness: an empirical assessment of the applicability of the Nonaka-Takeuchi model to the management of the selling function. Marketing Intelligence and Planning, 9, 188-199.

BLACKLER, F. (1995) Knowledge, knowledge work and organizations: An overview and interpretation. Organization Studies, 16, 1021-1046.

BOISOT, M. (1998) Knowledge assets: securing competitive advantage in the information economy, New York, Oxford University Press.

BOSUA, R. \& SCHEEPERS, R. (2007) Towards a model to explain knowledge sharing in complex organizational environments. Knowledge Management Research and Practice, 5, 93-109.

BRANNBACK, M. (2003) R\&D collaboration: role of Ba in knowledgecreating networks. Knowledge Management Research and Practice, 1, 2838.

BRANNBACK, M., CARSRUD, A. \& SCHULTE, W. D. (2008). Exploring the role of $\mathrm{Ba}$ in family business context. VINE: The journal of information and knowledge management systems, 38, 104-117.

BRYCESON, K. (2007) The online learning environment - A new model using social constructivism and the concept of ' $\mathrm{Ba}^{\prime}$ ' as a theoretical framework. Learning Environ Res, 10, 189-206. 
BURTON, C. L. (2002). Knowledge Transfer in a Corporate Setting: a case study. Ph.D. School of Education: Indiana University.

CHOO, C. W. (1998) The knowing organization : how organizations use information to construct meaning, create knowledge, and make decisions, New York, Oxford University Press.

CHOU, S. W. \& WANG, S. J. (2003) Quantifying 'ba': an investigation of the variables that are pertinent to knowledge creation. Journal of Information Science, 29, 167-180.

CORNO, F., REINMOELLER, P. \& NONAKA, I. (1999) Knowledge Creation within Industrial Systems. Journal of Management and Governance, 3, 379-394.

CUELLAR, M. J. \& GALLIVAN, M. J. (2006) A framework for ex ante project risk assessment based on absorptive capacity. European Journal of Operational Research, 173, 1123-1138.

FAYARD, P. (2003) Strategic communities for knowledge creation: a Western proposal for the Japanese concept of Ba. Journal of Knowledge Management, 7, 25-31.

FORD, R. \& ANGERMEIER, I. (2004) Managing the knowledge environment: a case study from healthcare. Knowledge Management Research \& Practice,2, 137-146.

GOLD, A. H., MALHOTRA, A. \& SEGARS, A. H. (2001) Knowledge management: An organizational capabilities perspective. Journal of Management Information Systems, 18, 185-214.

HANSSON, F. (2007) Science parks as knowledge organizations - the "ba" in action? European Journal of Innovation Management, 10, 248-366.

INKPEN, A. C. (1996) Creating knowledge through collaboration. California Management Review, 39, 123-\&.

JACKSON, M. C. (2005) Reflections on knowledge management from a critical systems perspective. Knowledge Management Research \& Practice, 3, 187-196.

JYRAMA, A. \& AYVARI, A. (2005) Fostering learning - the role of mediators. Knowledge Management Research \& Practice, 5, 117-125.

JOHNSON, W.H.A. (2000) Technological innovation and knowledge creation: a study of the enabling conditions and processes of knowledge creation in collaborative $R \& D$ projects. Ph.D. Schulich School of Business: York University, Canada.

KODAMA, M. (2005) Knowledge creation through networked strategic communities - Case studies on new product development in Japanese companies. Long Range Planning, 38, 27-49. 
KODAMA, M. (2005) New knowledge creation through leadership-based strategic community - a case of new product development in IT and multimedia business fields. Technovation, 25, 895-908.

$\mathrm{KOH}$, J. \& KIM, Y. G. (2004) Knowledge sharing in virtual communities: an e-business perspective. Expert Systems with Applications, 26, 155-166.

KOSTIAINEN, J. (2002) Learning and the 'ba' in the development network of an urban region. European Planning Studies, 10, 613-631.

LECHNER, C. \& DOWLING, M. (2003) Firm networks: external relationships as sources for the growth and competitiveness of entrepreneurial firms. Entrepreneurship and Regional Development, 15, 126.

LEE, H. \& CHOI, B. (2003) Knowledge management enablers, processes, and organizational performance: An integrative view and empirical examination. Journal of Management Information Systems, 20, 179-228.

MATURANA, H. \& VARELA, F. (1987). The tree of Knowledge. Boston, MA: New Science Library.

MILES, M. \& HUBERMAN, A. (1984). Qualitative data analysis: a sourcebook of new methods. Newbury Park, California: Sage Publications.

MILES, R. E., SNOW, C. C. \& MILES, G. (2000) The Future.org. Long Range Planning, 33, 300-321.

NAKAMORI, Y. (2006) Designing, utilizing and evaluating 'Technologycreating Ba' in a Japanese scientific research institution. Systems Research and Behavioral Science, 23, 3-19.

NISHIDA, K. (1990) An Inquiry into the Good (1921), as translated by M. Abe and C. Ives, Yale University, New Haven, CT

NOMURA, T. (2002) Design of 'Ba' for successful Knowledge Management - how enterprises should design the places of interaction to gain competitive advantage. Journal of Network and Computer Applications, $25,263-278$.

NONAKA, I. (1991) THE KNOWLEDGE-CREATING COMPANY. Harvard Business Review, 69, 96-104.

NONAKA, I. \& KONNO, N. (1998) The concept of "ba": Building a foundation for knowledge creation. California Management Review, 40, 40-54.

NONAKA, I. \& NISHIGUCHI, T. (2001). Knowledge emergence: social, technical, and evolutionary dimensions of knowledge creation. New York: Oxford University Press.

NONAKA, I., REINMOELLER, P. \& SENOO, D. (1998) IThe 'ART' of Knowledge: Systems to Capitalize on Market Knowledge. European Management Journal, 16, 673-684. 
NONAKA, I. \& TAKEUCHI, H. (1995). The Knowledge-creating Company: How Japanese Companies Create the Dynamics of Innovation. New York: Oxford University Press.

NONAKA, I. \& TOYAMA, R. (2002) A firm as a dialectical being: towards a dynamic theory of a firm. Industrial and Corporate Change, 11, 995-1009.

NONAKA, I. \& TOYAMA, R. (2003) The knowledge-creating theory revisited: knowledge creation as a synthesizing process. Knowledge Management Research \& Practice, 1, 2-10.

NONAKA, I. \& TOYAMA, R. (2007) Strategic management as distributed practical wisdom (phronesis). Industrial and Corporate Change, 16, 371394.

NONAKA, I., TOYAMA, R. \& KONNO, N. (2000) SECI, ba and leadership: a unified model of dynamic knowledge creation. Long Range Planning, 33, 5-34.

NONAKA, I., VON KROGH, G. \& VOELPEL, S. (2006) Organizational knowledge creation theory: Evolutionary paths and future advances. Organization Studies, 27, 1179-1208.

PAN, S. L. \& LEIDNER, D. E. (2003) Bridging communities of practice with information technology in pursuit of global knowledge sharing. Journal of Strategic Information Systems, 12, 71-88.

PELTOKORPI, V., NONAKA, I. \& KODAMA, M. (2007) NTT DoCoMo's launch of i-mode in the Japanese mobile phone market: A knowledge creation perspective. Journal of Management Studies, 44, 50-72.

PÉREZ-BUSTAMANTE, G. (1999) Knowledge Management in agile innovative organizations. Journal of Knowledge Management, 3, 6-17.

ROTH, J. (2003) Enabling Knowledge Creation: learning from an R\&D organization. Journal of Knowledge Management, 7, 32-48.

SABHERWAL, R. \& BECERRA-FERNANDEZ, I. (2003) An empirical study of the effect of knowledge management processes at individual, group, and organizational levels. Decision Sciences, 34, 225-260.

SAWHNEY, M. \& PRANDELLI, E. (2000) Communities of creation: Managing distributed innovation in turbulent markets. California Management Review, 42, 24-+.

SENOO, D., MAGNIER-WATANABE, R. \& SALMADOR, M. (2007) Workplace reformation, active ba and knowledge creation: from a conceptual to a practical framework. European Journal of Innovation Management, 10, 296-315.

SEUFERT, S. (XXXX) Work-Based Learning and Knowledge Management: An

integrated Concept of Organizational Learning.

SEUFERT, A., VON KROGH, G. \& BACH, A.(1999) Towards Knowledge 
Networking. Journal of Knowledge Management, 3, 180-190.

SHIMIZU, H. (1995) Ba-principle: new logic for the real-time emergence of

information,Holonics, 5(1), 67-79.

TSOUKAS, H. (2005) Complex Knowledge: studies in organizational epistemology. New York: Oxford University Press.

TEE, M.Y. (2005). Tacit knowledge in a e-learning environment: a naturalistic study. Ph.D. University of Kansas.

VON KROGH, G. (1998) Care in knowledge creation. California Management

Review, 40, 133-+.

VON KROGH, G., ICHIJO, K. \& NONAKA, I. O. (2000) Enabling knowledge creation: how to unlock the mystery of tacit knowledge and release the power of innovation, Oxford ; New York, Oxford University Press.

VON KROGH, G., KIM, S. \& ERDEN, Z. (2008) Fostering the knowledgesharing behavior of customers in interorganizational healthcare communities. IN CAO, J., LI, M. L., WENG, C. L., XIANG, Y., WANG, X., TANG, H., HONG, F., LIU, H. \& WANG, Y. L. (Eds.) IFIP International Conference on Network and Parallel Computing. Shanghai, PEOPLES R CHINA, Ieee Computer Soc.

VON KROGH, G., NONAKA, I. \& ICHIJO, K. (1997). Develop Knowledge Activists! European Management Journal, 15, 475-483.)

WU, C. N. (2008) Knowledge creation in a supply chain. Supply Chain Management-an International Journal, 13, 241-250.

ZARRAGA, C. \& BONACHE, J. (2005) The impact of team atmosphere on knowledge outcomes in self-managed teams. Organization Studies, 26, 661-681.

ZHU, Z. (2004) Knowledge management: towards a universal concept or cross-cultural contexts? Knowledge Management Research \& Practice, 2, 67-79.

i 592 papers plus 2 of Nonaka's et al. papers not $\mathrm{H}$-Index 4 . One of these 2 papers was not available, therefore the final sum of 593 papers. 